\title{
A Rare Infectious Cause of Optic Neuritis
}

\author{
Shuwei Wang, MD, Drew Kotler, MD, and Mitchell Sternlieb, MD
}

\section{INTRODUCTION}

Optic neuritis $(O N)$ is the most common type of inflammatory, demyelinating disorder of the optic nerve, most often caused by multiple sclerosis (MS). However, alternative diagnoses should be considered and investigated thoroughly in the setting of other systemic symptoms. Optic neuritis is a rare manifestation of Lyme disease that typically improves with antibiotics.

\section{CASE PRESENTATION}

A 50 year-old woman with history of breast cancer treated with mastectomy and chemotherapy in remission for ten years presented with a right-sided headache and right eye vision changes

She was feeling well until three weeks prior to hospital admission in June when she developed fevers up to $103.1^{\circ} \mathrm{F}$, sweats, and a circular, slightly raised and pruritic rash on her neck, chest and on her right lower extremity. She was evaluated at an urgent care clinic where a rapid strep test was negative, and she was sent home without antibiotics. Over the next three days, fevers and rash resolved without treatment. Two weeks afterward, the patient developed a right-sided headache associated with right eye pain and intermittent blurry vision. She denied neck stiffness, joint pain, rash, or myalgias at that time. Outpatient ophthalmic evaluation revealed right optic disc edema and MRI of the brain showed enhancement along the right optic nerve. The patient had hiked in wooded areas in the Philadelphia region in the spring and summer months but was not aware of any mosquito or tick bites. Her allergies include an unknown allergy to oxytetracycline.

On admission, she was afebrile and vital signs were normal. Ophthalmologic exam showed right optic disc edema and 20/25 visual acuity in both eyes. The left eye exam and remainder of her physical exam were unremarkable. Her complete blood count and basic metabolic panel were normal.

A photograph of the patient's rash from three weeks prior demonstrated a flat red patch with central clearing involving her posterior right thigh.

\section{DIFFERENTIAL DIAGNOSIS}

The differential diagnosis for her visual complaints and findings include early disseminated Lyme disease, neurosyphilis, neurosarcoidosis, perioptic meningioma, lymphoma, metastatic breast cancer, multiple sclerosis, acute demyelinating encephalomyelitis, neuromyelitis optica (NMO), and large vessel vasculitides including giant cell arteritis.

\section{OUTCOME AND FOLLOW-UP}

The patient underwent a lumbar puncture with an opening pressure of $11 \mathrm{~cm} \mathrm{H}_{2} \mathrm{O}$.

The patient had extensive blood and cerebrospinal fluid testing (CSF) (Tables 1 and 2).

Table 1. Serum studies

\begin{tabular}{|c|c|}
\hline BLOOD TESTING & RESULTS \\
\hline Lyme Disease Antibody & Reactive \\
\hline $\begin{array}{l}\text { Serum Immunoglobulin } \\
M(\lg M) \text { Western Blot }\end{array}$ & $\begin{array}{l}\text { Lyme Ab IgM, WB Positive } \\
\text { Lyme } 23 \text { kD IgM Reactive } \\
\text { Lyme } 39 \text { kD IgM Reactive } \\
\text { Lyme } 41 \text { kD IgM Reactive }\end{array}$ \\
\hline $\begin{array}{l}\text { Serum Immunoglobulin } \\
G(\lg G) \text { Western Blot }\end{array}$ & $\begin{array}{l}\text { Lyme Ab lgG, WB Negative } \\
\text { Lyme } 18 \text { kD IgG Nonreactive } \\
\text { Lyme } 23 \text { kD IgG Reactive } \\
\text { Lyme } 28 \text { kD IgG Nonreactive } \\
\text { Lyme } 30 \text { kD IgG Nonreactive } \\
\text { Lyme } 39 \text { kD IgG Reactive } \\
\text { Lyme } 41 \text { kD lgG Reactive } \\
\text { Lyme } 45 \text { kD IgG Nonreactive } \\
\text { Lyme } 58 \text { kD IgG Nonreactive } \\
\text { Lyme } 66 \text { kD IgG Nonreactive } \\
\text { Lyme } 93 \text { kD IgG Nonreactive }\end{array}$ \\
\hline Rapid Plasma Reagin (RPR) & Nonreactive \\
\hline Quantiferon TB Gold Test & Negative \\
\hline NMO IgG Antibody & Negative \\
\hline
\end{tabular}


Table 2. CSF studies

\begin{tabular}{|c|c|}
\hline CSF STUDIES & RESULTS (reference range) \\
\hline Fluid Cell Count & $\begin{array}{l}20 \text { Red Blood Cells } \\
2 \text { White Blood Cells }\end{array}$ \\
\hline Protein & $26 \mathrm{mg} / \mathrm{dL}(15-55)$ \\
\hline Glucose & $62 \mathrm{mg} / \mathrm{dL}(40-70)$ \\
\hline Gram Stain & No organisms seen \\
\hline Aerobic/Anaerobic Culture & No growth \\
\hline $\begin{array}{l}\text { Venereal Disease Research } \\
\text { Laboratory (VDRL) }\end{array}$ & Negative \\
\hline Cryptococcal Antigen & Nonreactive \\
\hline $\begin{array}{l}\text { Lyme polymerase chair } \\
\text { reaction (PCR) }\end{array}$ & Positive \\
\hline $\begin{array}{l}\text { Angiotensin Converting } \\
\text { Enzyme (ACE) level }\end{array}$ & $8 \mathrm{mcg} / \mathrm{L}(<=15)$ \\
\hline NMO/AQP4-IgG CBA & Negative \\
\hline Myelin basic protein level & $<2.0 \mathrm{ng} / \mathrm{mL}(0-4)$ \\
\hline Oligoclonal Bands & $\begin{array}{l}\text { Pathology report: The patient's } \\
\text { CSF contains } 2 \text { well defined } \\
\text { gamma restriction bands that } \\
\text { are also present in the patient's } \\
\text { corresponding serum sample, } \\
\text { but some bands in the CSF are } \\
\text { more prominent. This pattern } \\
\text { is associated with Guillain- } \\
\text { Barre's syndrome, peripheral } \\
\text { neuropathy or increased } \\
\text { permeability of the blood-brain } \\
\text { barrier secondary to infection } \\
\text { or trauma. }\end{array}$ \\
\hline Protein Electrophoresis & Normal \\
\hline Cytology & Negative for malignancy \\
\hline
\end{tabular}

She was diagnosed with acute optic neuritis secondary to early disseminated Lyme disease based on positive serum Lyme disease serologies, recent erythema migrans rash, epidemiology, and positive CSF Lyme PCR. The normal CSF levels of angiotensin converting enzyme (ACE), NMO/Aquaporin-4-IgG antibody, and myelin basic protein made neurosarcoidosis, neuromyelitis optica, and multiple sclerosis, less likely. MRI of the brain and orbits demonstrated asymmetric enlargement and perineural circumferential enhancement of the right optic nerve from the optic disc to the right optic canal (Figure 1).

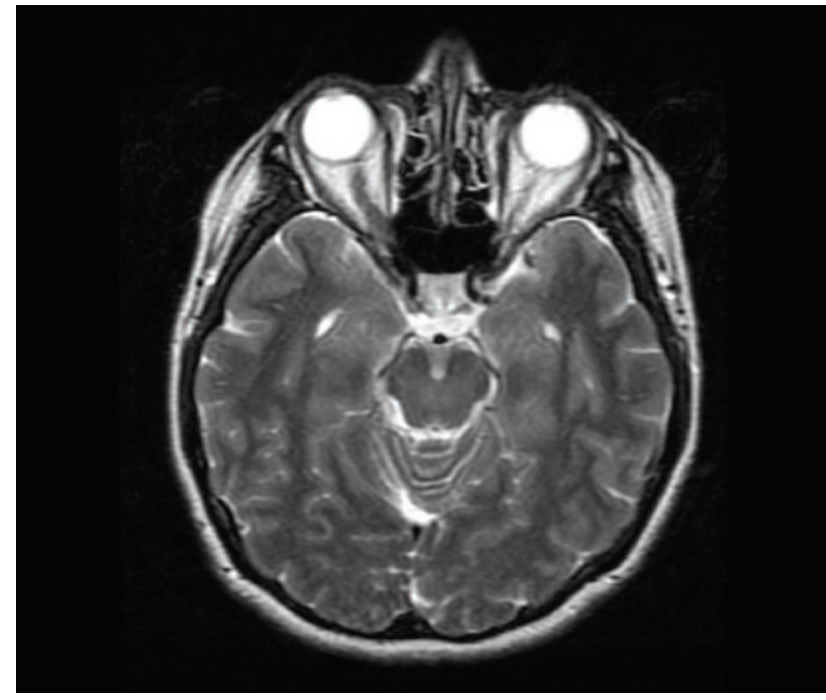

Figure 1. R optic nerve enhancement with asymmetric enlargement of the right optic nerve/sheath complex from the level of the optic disk where it appears to be enlarged to the level of the right optic canal and associated with perineural circumferential enhancement of the optic nerve sheath.

She was started on IV ceftriaxone 2 g every 24 hours for a total of 14 days in conjunction with a short course of methylprednisolone. She was not treated with doxycycline given her allergy to oxytetracycline. Her blurry vision and headache improved significantly and a follow up MRI of the brain 2 months later showed resolution of the above findings (Figure 2).

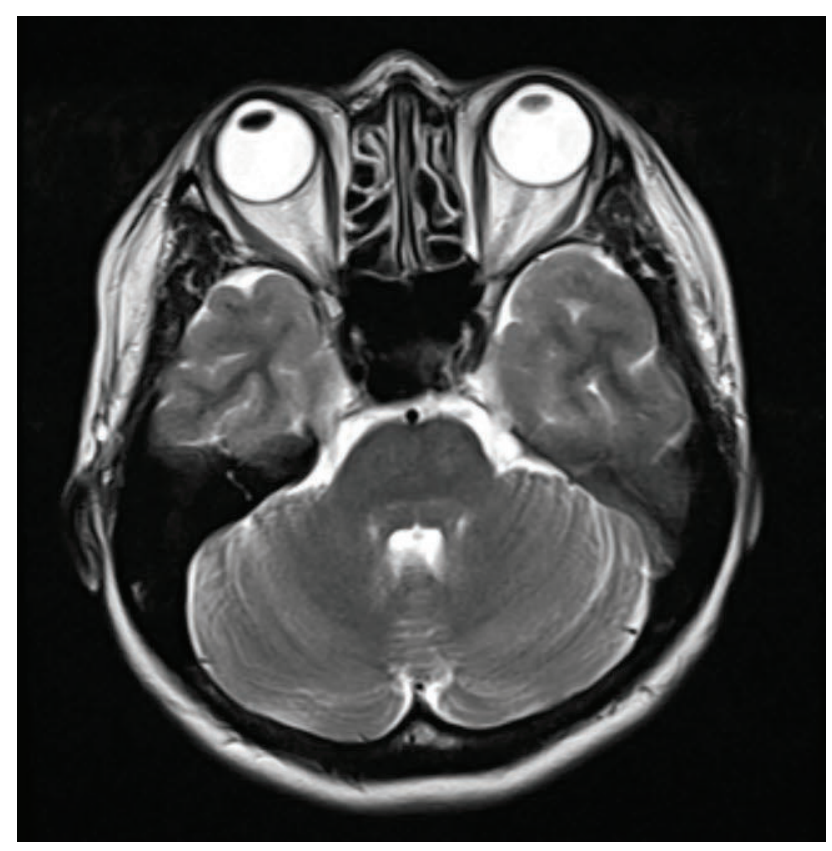

Figure 2. Significant improvement/resolution of abnormal signal and enhancement of the right optic nerve in keeping with Lyme optic neuritis. No new areas of abnormal signal or enhancement in the brain or orbits. 


\section{DISCUSSION}

Optic neuritis, an inflammatory demyelination of the optic nerve, causes acute monocular visual loss. Causative etiologies comprise a broad differential including multiple sclerosis, systemic lupus erythematosus, infection (Lyme disease, toxoplasmosis, Bartonella henselae, Mycobacterium tuberculosis, human immunodeficiency virus, West Nile virus, parvovirus B19, and some Herpes viruses) and neoplasms. Prompt diagnosis of infectious causes allows for timely antibiotic administration and potential reversal of the vision loss.

Lyme disease is a multisystem infection with the nervous system involved in 10 to 15 percent of infected individuals. The spirochete Borrelia burgdorferi is carried by the Ixodes tick. Following a bite from the tick, the spirochete first invades locally and then disseminates hematogenously to various organs including the central and peripheral nervous systems ${ }^{1}$. Lymphocytic meningitis, cranial neuropathy (most commonly facial nerve palsy), and radiculoneuritis form the classic triad of acute early neurologic Lyme disease. Ocular complications of Lyme disease include conjunctivitis, keratitis, extra-ocular muscle palsies, and acute optic neuritis².

Cranial neuropathies and radiculoneuritis are thought to share similar neurophysiologic patterns of a multifocal, patchy inflammatory process affecting the peripheral nerve, namely a mononeuritis multiplex ${ }^{3}$. However, it has been more challenging to describe the pathophysiology of optic neuritis; the optic nerve function resembles central nervous system (CNS) function similar to parenchymal brain involvement. Rupprecht et al. postulate that local immune cells secrete cytokines in response to spirochete presence in the CNS, which directly injures neurons and leads to the lymphocytic pleocytosis seen in the $\mathrm{CSF}^{5}$.

A number of factors make establishing a causal relationship between optic neuritis and Lyme disease challenging. The incidence of optic neuritis attributable to Lyme is low, even in Lyme-endemic regions. Asymptomatic seropositivity to B. burgdorferi (false positive or prior infection) in endemic areas further complicates the diagnosis. In a retrospective analysis of Lyme serologies in 440 patients with optic neuritis, Sibony et al. defined a rigorous set of criteria and, applying these, found only a strong causal link between Lyme disease and papillitis and posterior uveitis but not with optic neuritis. According to their criteria, definitive proof of a causal link requires identification of organism by culture or tissue histology from the CSF or optic nerve in a patient with clinically active Lyme disease and optic neuritis. To meet criteria for the next category, labeled "strong evidence", patients must have optic neuritis, endemic exposure, exclusion of syphilis and multiple sclerosis, and a positive serum Lyme titer in association with at least one of the following: 1) encephalitis or meningitis with CSF pleocytosis, intrathecal antibody production, or CSF PCR positive for B. burgdorferi DNA, and a positive Western blot; 2) recent erythema migrans; and 3) recent signs of Lyme disease, such as facial nerve palsy, arthritis, or radiculoneuritis with positive serum ELISA confirmed by Western blot ${ }^{4}$. This patient meets the criteria to suggest strong evidence for causality between her optic neuritis and Lyme disease. Review of the literature revealed no cases that definitively demonstrated causation, based on the criteria above, of Lyme optic neuritis.

Most patients described with symptoms and studies concerning for Lyme optic neuritis responded to antibiotics with good outcomes ${ }^{4,6-8}$. Differences exist between European, which rely on oral doxycycline, and the United States' guidelines for management of Neuroborreliosis ${ }^{9}$. In the United States, the 2006 Infectious Disease Society of America guidelines only recommend oral doxycycline for patients with isolated facial nerve palsy without abnormal CSF findings, meningitis, or radiculoneuritis. Intravenous ceftriaxone, cefotaxime, or penicillin $G$ is recommended when abnormal CSF findings are present ${ }^{10}$. Ceftriaxone was the treatment used for most of the reported Lyme optic neuritis cases. The role of adjunctive corticosteroids remains unclear ${ }^{11}$.

In conclusion, optic neuritis due to Lyme disease remains difficult to prove. Herein we presented a case of a patient with epidemiology and clinical features consistent with recent Lyme infection with subjective and objective visual abnormalities that developed a few weeks later. CSF and serum studies for Borrelial antibodies and DNA demonstrated, at a minimum, presence of spirochetes in the CNS. Short of direct visualization of organisms in the optic nerve and in the absence of an alternative diagnosis, these studies suggest strong evidence for causation.

\section{KEY POINTS}

- It is important to consider Lyme disease in the differential diagnosis in patients from Lyme endemic areas who present with optic neuritis.

- Most patients with probable Lyme optic neuritis respond favorably to IV ceftriaxone but the role of corticosteroids remains controversial.

- There is need for more specific diagnostics to prove Borrelial involvement of the optic nerve 


\section{REFERENCES}

1. Rizzoli A, Hauffe H, Carpi G, et al. Lyme borreliosis in Europe. Euro Surveill 2011; 16:1-8.

2. Lesser, R.L. Ocular manifestations of Lyme disease. Am J Med. 1995:98:60S-62S

3. Halperin JJ. Nervous system Lyme disease: is there a controversy? Semin Neurol 2011; 31:317-324

4. Sibony P, Halperin J, Coyle PK, Patel K. Reactive Lyme serology in optic neuritis. Journal of Neuro-Ophthalmology 2005; 25(2):71-82.

5. Rupprecht TA, Koedel U, Fingerle V, Pfister HW. The pathogenesis of Lyme neuroborreliosis: from infection to inflammation. Mol Med 2008; 14:205-212

6. Jacobson DM. Lyme disease and optic neuritis: long-term follow-up of seropositive patients. Neurology 2003; 60(5):881-2.

7. Krim E, Guehl D, Burbaud P, Lagueny A. Retrobulbar optic neuritis: a complication of Lyme disease? J Neurol Neurosurg Psychiatry 2007 78(12):1409-10

8. Rothermel H, Hedges 3rd TR, Steere AC. Optic neuropathy in children with Lyme disease. Pediatrics 2001; 108(2):477-81

9. Karlsson M, hammers-Berggren $S$, Lindquist $L$, et al. Comparison of intravenous penicillin $\mathrm{G}$ and oral doxycycline for treatment of Lyme neuroborreliosis. Neurology 1994; 44:1203.

10. Wormser GP, Dattwyler RJ, Shapiro Ed, et al. The clinical assessment, treatment, and prevention of lyme disease, human granulocytic anaplasmosis, and babesiosis: clinical practice guidelines by the Infectious Disease Society of America. Clin Infect Dis 2006; 43:1089.

11. Blanc F., Ballonzoli L., Marcel C., De Martino S., Jaulhac B., de Seze J., Lyme optic neuritis. Journal of the Neurological Sciences 2010; 295(1): 117-119.

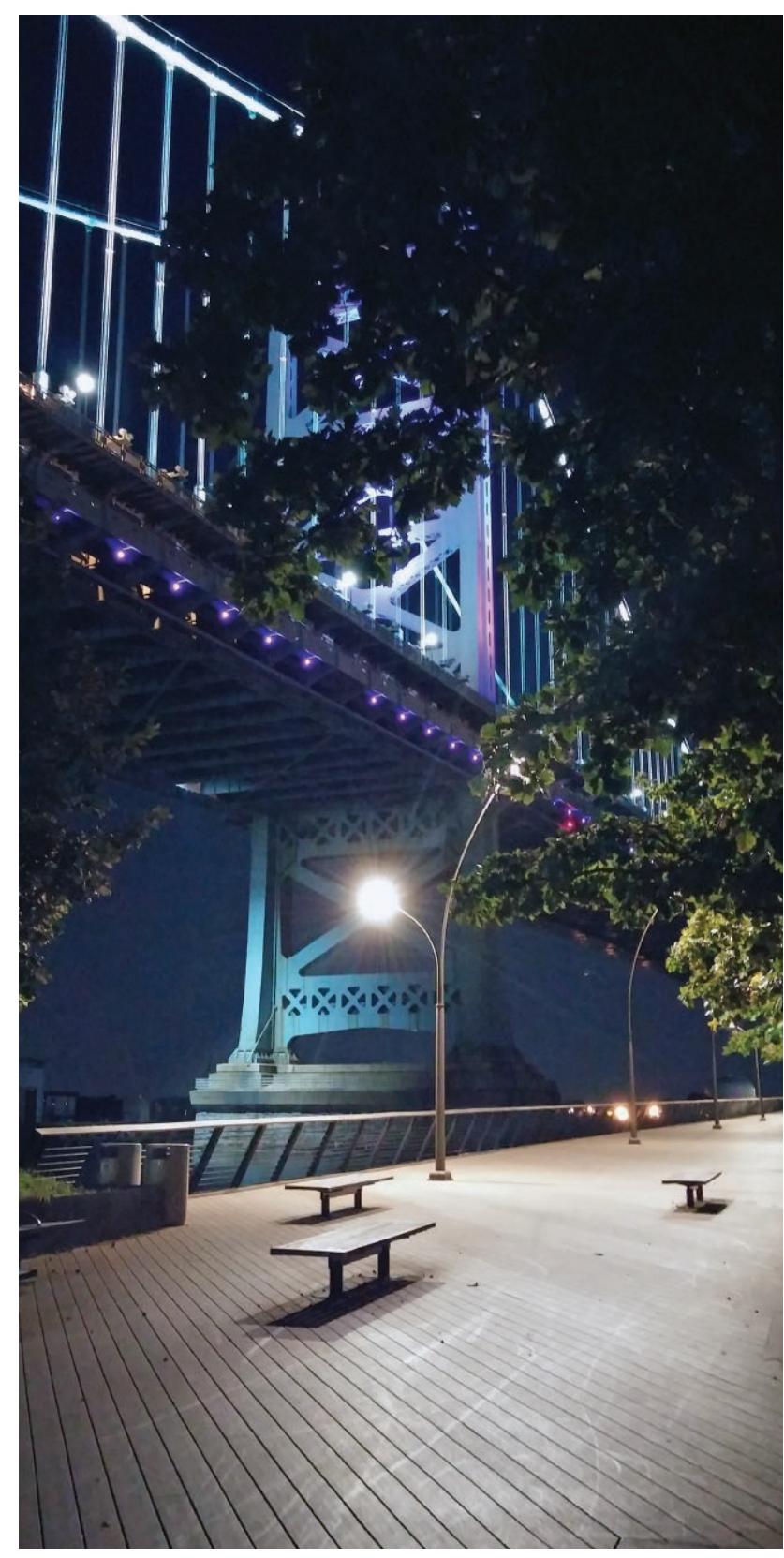

Anita Modi, MD 